\title{
Analysis of Esophageal Cancer Death at Different Educational Levels in Inner Mongolia from 2009 to 2015
}

\author{
Rina Su, Hao Wu, Fengqing Li, Yan Zhang, Huixia Li, Lin Sun, Sitana Ha, Junjie An, \\ Chengyi Zhang, Juan Sun*
}

Inner Mongolia Honder College of Arts and Sciences, Huhhot, China

Email: *sj6840@163.com

How to cite this paper: $\mathrm{Su}, \mathrm{R} . \mathrm{N} ., \mathrm{Wu}, \mathrm{H}$., Li, F.Q., Zhang, Y., Li, H.X., Sun, L., Ha, S.T.N., An, J.J., Zhang, C.Y. and Sun, J. (2021) Analysis of Esophageal Cancer Death at Different Educational Levels in Inner Mongolia from 2009 to 2015. Health, 13, 1270-1277.

https://doi.org/10.4236/health.2021.1311092

Received: September 18, 2021

Accepted: November 13, 2021

Published: November 16, 2021

Copyright $\odot 2021$ by author(s) and Scientific Research Publishing Inc. This work is licensed under the Creative Commons Attribution International License (CC BY 4.0).

http://creativecommons.org/licenses/by/4.0/

(c) (i) Open Access

\begin{abstract}
Objective: This study aimed to clarify the death characteristics of esophageal cancer in Inner Mongolia and the population distribution with various education levels. Methods: The mortality rate of esophageal cancer was calculated using the monitoring point of Death Registry System in Inner Mongolia from 2009 to 2015. The gender, age, region, ethnicity at two education levels of percentage were calculated and the $\chi^{2}$ test was executed. Result: The mortality rate of esophageal cancer was $10.10 / 10^{5}$, China Adjustment Mortality was $10.97 / 10^{5}$, World Adjustment Mortality was $9.08 / 10^{5}$ in Inner Mongolia. The death of esophageal cancer showed statistical significance at two educational levels $(\mathrm{P}<0.05)$. High school and below accounted for $93.9 \%$ at the education level, and above high school accounted for $3.5 \%$. In addition, there were significant differences in the percentage of death by gender, age and region at two educational levels $(\mathrm{P}<0.05)$. Conclusion: Education level has a certain relation with the death of esophageal cancer. To improve the health level, health education plans can be formulated according to esophageal cancer prevention relevant policy with different education levels.
\end{abstract}

\section{Keywords}

Esophageal Cancer, Death, Education Level

\section{Introduction}

It was estimated that one in every 20 cancer deaths worldwide in 2018 was esophageal cancer [1]. A previous study reported that Chinese patients with esophageal cancer, liver cancer and stomach cancer account for nearly half of the 
global cancer cases [2]. Nearly $50 \%$ of the world's esophageal cancer cases occur in China [3]. Esophageal cancer related death was fourth in China in 2016, the mortality rate was $15.17 / 10^{5}$ [4]. The impact of esophageal cancer on human beings can't be underestimated. It can be seen that esophageal cancer had a higher death rate and worthy of paying attention. Many studies have shown that unreasonable dietary nutrition, alcohol, tobacco and other factors can increase the risk of esophageal cancer [5] [6]. However, there are relatively less studies on the general characteristics of the population in Inner Mongolia, especially the correlation between education level and esophageal cancer.

There is a close correlation between educational levels and mortality rates [7]. A relevant study has investigated six regions in China (North China, Northeast China, East China, Central South, Southwest, Northwest). The results showed that the mortality in the six regions of China is different [8]. The higher the education level, the lower the mortality [8]. Besides educational level the research showed that age, marriage and occupation were closely related to mortality [9]. At the beginning of the century, we have studied digestive system cancer and had corresponding research results [10]. This study will further investigate the characteristics of esophageal cancer death in one of the digestive system cancers in Inner Mongolia.

\section{Materials and Methods}

\subsection{Data Source}

Data were obtained from Death Registry System (DRS) in the Inner Mongolia Centers for Disease Control and Prevention (CDC), 2009 to 2015. There were eight monitoring points from 2009 to 2012 . The monitoring points were twenty from 2013 to 2015. The monitoring points were selected by the method of multi-stage stratified cluster random sampling [11]. The monitoring points covered the eastern, central and western regions of Inner Mongolia, including urban and rural areas. The permanent resident population in 2009-2012 was 2.4 million, accounting for about $10 \%$ of Inner Mongolia population. The permanent resident population in 2013-2015 was 5.8 million, accounting for about $23 \%$ of the Inner Mongolia population. The cause of death data was taken as the information of the death with esophageal cancer according to several methods, such as clinical diagnosis, surgery, pathological diagnosis, laboratory tests and postmortem inferences [12]. According to the International Classification of Diseases (ICD-10) criteria, the ICD underlying cause of death code ranges from C15.0 to C15.9 [13].

The researchers summarized the death data of esophageal cancer in monitoring points in Inner Mongolia from 2009 to 2015. Combined with demographic characteristics, required data were classified. There were diagnostic methods, education level, age, ethnicity and other factors. We divided diagnostic methods into clinical diagnosis and laboratory tests, including clinical, physical and chemistry examination, as well as pathological diagnosis, surgical diagnosis and 
posthumous diagnosis. There was only one clear demarcation in high school among various educational levels by the DRS of Inner Mongolia CDC. We had to divide education levels into high school and below, including high school, technical school, junior high school, primary school, illiterate or semi-illiterate; above high school, including college, graduate students; Unknown, education level is not indicated. We divided age into five groups, $<45,45-, 55-, 65-, 75+$. The number of esophageal cancer deaths in different age groups under 45 years old was very small. Therefore, this study divided the age group under 45 years old into a single group. We divided ethnicity into The Mongol Ethnicity, including Mongolia, Evenki and Daur; The Han Ethnicity; Others, Including the Hui, Manchu.

\subsection{Statistical Analysis}

The researchers calculated the seven-year average mortality rate of esophageal cancer (Mortality $=$ The number of deaths/population $\times 100,000)$ and china adjustment mortality (CAM), and world adjustment mortality (WAM). The percentage of esophageal cancer by sex, age, region and ethnicity with different education levels was calculated. The $\chi^{2}$ test was used to compare the effects of different population characteristics on death from esophageal cancer. $\mathrm{P} \leq 0.05$ indicated statistical significance. The above data were calculated and analyzed using Microsoft excel and SPSS 22.0 statistical analysis software.

\section{Result}

Table 1 presented the diagnosis distribution of esophageal cancer monitoring points in Inner Mongolia between 2009 and 2015. 2750 people died from esophageal cancer; clinical and laboratory tests, pathological diagnosis and surgical diagnosis accounted for $97.8 \%$ of the esophageal cancer deaths between 2009 and 2015 in Inner Mongolia.

Table 2 presented the death data of each year on esophageal cancer from 2009 to 2015 , ranging from $9.30 / 10^{5}$ to $11.48 / 10^{5}$. The average mortality rate of esophageal cancer in Inner Mongolia monitoring points was $10.10 / 10^{5}$, the average CAM was $10.97 / 10^{5}$, and the average WAM was $9.08 / 10^{5}$. Males and females mortality rates were $16.79 / 10^{5}$ and $2.82 / 10^{5}$, respectively. Males were 5.95 times higher in females. The male of CAM was $18.00 / 10^{5}$, and WAM was $14.18 / 10^{5}$. The female of CAM was $3.36 / 10^{5}$, and WAM was $3.02 / 10^{5}$. The maximum mortality rate of esophageal cancer in Inner Mongolia between 2009-2015 was 11.48/ $10^{5}$ and a minimum was $9.30 / 10^{5}$. There was no significant change trend observed during seven years $(\mathrm{P}>0.05)$.

The esophageal cancer death in high school and below was $93.9 \%$ and above high school was $3.5 \%$. Table 3 presents the demographic characteristics of esophageal cancer deaths at various educational levels. The results showed significant differences in the demographic characteristics percentage of esophageal cancer deaths at various educational levels $(\mathrm{P}<0.05)$, except for ethnicity. In 
Table 1. Diagnostic distribution of esophageal cancer monitoring points in Inner Mongolia between 2009 to 2015.

\begin{tabular}{|c|c|c|c|}
\hline & Number of deaths & Percentage (\%) & Cumulative percentage (\%) \\
\hline \multicolumn{4}{|l|}{ Diagnostic method } \\
\hline Clinical Diagnosis and Laboratory tests & 1880 & 68.4 & 68.4 \\
\hline Pathological Diagnosis & 701 & 25.5 & 93.9 \\
\hline Surgical Diagnosis & 107 & 3.9 & 97.8 \\
\hline Posthumous Inference & 48 & 1.7 & 99.5 \\
\hline Unknown & 14 & 0.5 & 100.0 \\
\hline
\end{tabular}

Table 2. Mortality of esophageal cancer in monitoring points Inner Mongolia $\left(1 / 10^{5}\right)$.

\begin{tabular}{|c|c|c|c|c|c|c|c|c|c|c|c|c|}
\hline \multirow[b]{2}{*}{ Year } & \multicolumn{4}{|c|}{ Total Number of deaths } & \multicolumn{4}{|c|}{ Male } & \multicolumn{4}{|c|}{ Female } \\
\hline & $\begin{array}{l}\text { Number } \\
\text { of deaths }\end{array}$ & $\begin{array}{c}\text { Mortality } \\
\text { rate }\end{array}$ & CAM & WAM & $\begin{array}{l}\text { Number } \\
\text { of deaths }\end{array}$ & $\begin{array}{c}\text { Mortality } \\
\text { rate }\end{array}$ & CAM & WAM & $\begin{array}{l}\text { Number } \\
\text { of deaths }\end{array}$ & $\begin{array}{c}\text { Mortality } \\
\text { rate }\end{array}$ & CAM & WAM \\
\hline $2009^{*}$ & 274 & 11.48 & 14.60 & 12.37 & 240 & 19.68 & 24.01 & 14.08 & 34 & 2.91 & 4.09 & 3.73 \\
\hline $2010^{*}$ & 232 & 9.69 & 10.96 & 8.96 & 199 & 16.28 & 18.06 & 14.08 & 33 & 2.82 & 3.60 & 3.21 \\
\hline $2011^{\star}$ & 224 & 9.30 & 10.17 & 8.40 & 201 & 16.07 & 17.19 & 13.53 & 23 & 1.99 & 2.47 & 2.20 \\
\hline $2012^{\star}$ & 230 & 9.41 & 9.87 & 8.07 & 196 & 15.38 & 16.24 & 12.73 & 34 & 2.91 & 2.98 & 2.52 \\
\hline $2013^{*}$ & 556 & 9.57 & 10.58 & 8.70 & 480 & 15.69 & 17.26 & 13.55 & 76 & 2.77 & 3.37 & 3.02 \\
\hline $2014^{*}$ & 582 & 9.81 & 10.24 & 8.46 & 507 & 16.20 & 16.70 & 13.15 & 75 & 2.68 & 3.08 & 2.78 \\
\hline $2015^{\star}$ & 652 & 11.15 & 11.96 & 9.97 & 559 & 18.46 & 19.60 & 15.51 & 93 & 3.30 & 3.90 & 3.56 \\
\hline average & 2750 & 10.10 & 10.97 & 9.08 & 2382 & 16.79 & 18.00 & 14.18 & 368 & 2.82 & 3.36 & 3.02 \\
\hline $\mathrm{r}$ & & 0.036 & -0.179 & -0.179 & & -0.214 & -0.286 & -0.054 & & 0.090 & -0.143 & -0.143 \\
\hline $\mathrm{P}$ & & 0.939 & 0.702 & 0.702 & & 0.645 & 0.535 & 0.908 & & 0.848 & 0.760 & 0.760 \\
\hline
\end{tabular}

Table 3. The demographic characteristics of esophageal cancer deaths at various educational levels.

\begin{tabular}{|c|c|c|c|c|c|c|c|c|c|c|}
\hline & \multicolumn{2}{|c|}{ Total } & \multicolumn{2}{|c|}{ High School and Below } & \multicolumn{2}{|c|}{ Above High School } & \multicolumn{2}{|c|}{ Unknown } & \multirow[b]{2}{*}{$c^{2}$} & \multirow[b]{2}{*}{$\mathrm{P}$} \\
\hline & $\begin{array}{l}\text { Number } \\
\text { of deaths }\end{array}$ & $\begin{array}{c}\text { Percentage } \\
(\%)\end{array}$ & $\begin{array}{l}\text { Number } \\
\text { of deaths }\end{array}$ & $\begin{array}{c}\text { Percent-age } \\
(\%)\end{array}$ & $\begin{array}{l}\text { Number } \\
\text { of deaths }\end{array}$ & $\begin{array}{c}\text { Percentage } \\
(\%)\end{array}$ & $\begin{array}{l}\text { Number } \\
\text { of deaths }\end{array}$ & $\begin{array}{c}\text { Percent-age } \\
(\%)\end{array}$ & & \\
\hline Age & & & & & & & & & 31.791 & 0.000 \\
\hline$\leq 60$ & 980 & 35.6 & 904 & 35.0 & 59 & 60.8 & 17 & 23.6 & & \\
\hline$>60$ & 1770 & 64.4 & 1677 & 65.0 & 38 & 39.2 & 55 & 76.4 & & \\
\hline Gender & & & & & & & & & 13.681 & 0.001 \\
\hline Male & 2382 & 86.6 & 2234 & 86.6 & 93 & 95.9 & 55 & 76.4 & & \\
\hline Female & 368 & 13.4 & 347 & 13.4 & 4 & 4.1 & 17 & 23.6 & & \\
\hline Region & & & & & & & & & 22.689 & 0.000 \\
\hline East & 1873 & 68.1 & 1782 & 69.0 & 45 & 46.4 & 46 & 63.9 & & \\
\hline Mid-west & 877 & 31.9 & 799 & 31.0 & 52 & 53.6 & 26 & 36.1 & & \\
\hline
\end{tabular}




\section{Continued}

\begin{tabular}{cccccccccc}
\hline Ethnicity & & & & & & & & 0.212 & 0.995 \\
Mongol & 2021 & 73.5 & 1896 & 73.5 & 71 & 73.2 & 54 & 75.0 & \\
Han & 690 & 25.1 & 648 & 25.1 & 25 & 25.8 & 17 & 23.6 & \\
Others & 39 & 1.4 & 37 & 1.4 & 1 & 1.0 & 1 & 1.4 & \\
\hline
\end{tabular}

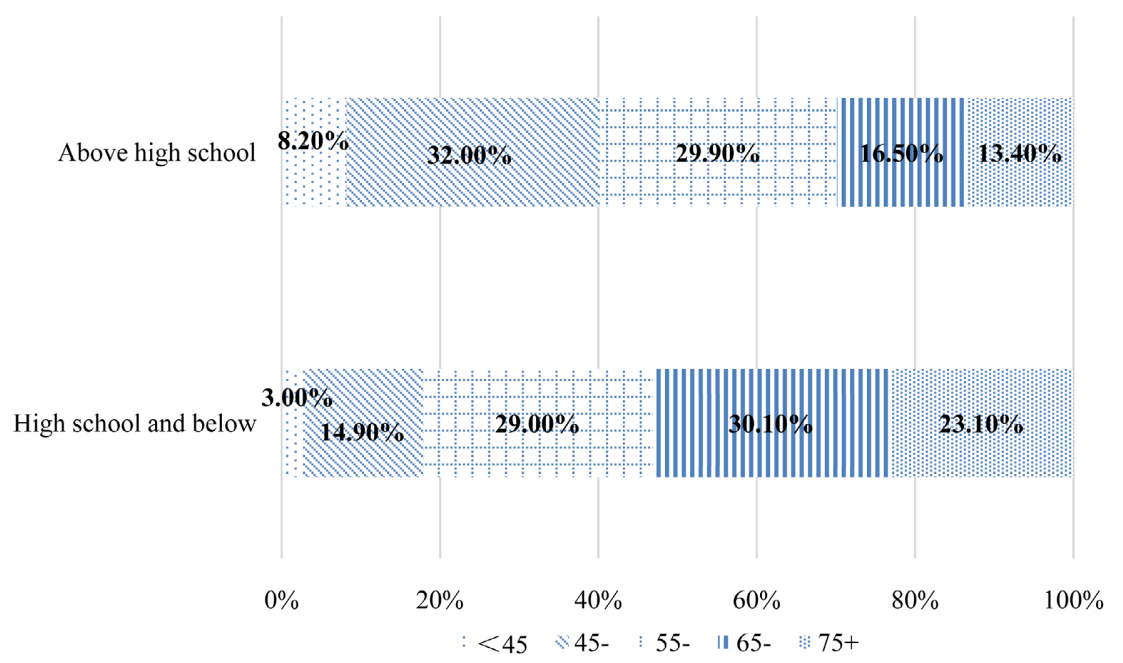

Figure 1. Age-specific death percentage of esophageal cancer between above high school, high school and below.

terms of age, in high school and below, the percentage of age $\leq 60$ deaths from esophageal cancer was $30 \%$ lower than for those $>60$. When the education level was above high school, the percentage of age $\leq 60$ deaths from esophageal cancer was $20.8 \%$ higher than for those $>60$. In terms of gender, the percentage of male death from high school and below was $73.2 \%$ higher than female. Male death from above high school was $91.8 \%$ higher than female. In terms of region, the percentage of high school and below death in the east was 38\% higher the midwest. The percentage of above high school in the east was $7.2 \%$ lower than in the mid-west, whether education level was high school and below or above. The death percentage of Han was higher than in Mongolian and other ethnic groups in high school and below or above. However, there was no significant difference between ethnicity and education level $(\mathrm{P}>0.05)$.

As shown in Figure 1, there were significant differences in the age-specific death percentage of esophageal cancer between above high school and high school and below in Inner Mongolia from 2009 to 2015 ( $\mathrm{P}<0.05)$. In terms of age-specific percentage, when the age was $<45,45-, 55-$, the education level of above high school was higher than the high school and below, $5.2 \%, 17.1 \%$ and $0.9 \%$, respectively. When the age is $65-$ and $75+$, the education level of above high school was lower than high school and below, $13.6 \%$ and 9.7\%, respectively. The highest percentage (32.0\%) of esophageal cancer death was age 45 - in the above high school. The highest percentage (30.1\%) of esophageal cancer death was age 65- in high school and below. 


\section{Discussion}

Monitoring death causes is an important indicator of the death level of a certain population in a particular period [14]. The average mortality rate of esophageal cancer in Inner Mongolia in seven years was higher than the world's $5.5 / 10^{5}$ in 2018. It was lower than China's $12.7 / 10^{5}$ in 2018 [15]. Compared with other regions in China, the mortality rate of esophageal cancer in Inner Mongolia was slightly higher than Fuzhou 2011-2019 [16], it was lower than Sichuan province in 2015 [17], and lower than Hebei province 2011-2016 [18]. Our results showed that the mortality rate of males was nearly six times higher than females, which is consistent with a previous study [19]. These findings indicate that male was more prone to esophageal cancer death. Possibly, there may have a certain relationship between the high proportion of male smoking and the different occupation and physiological structure in gender [20]. Therefore, we should pay more attention to the early diagnosis and treatment of esophageal cancer in males [18].

A previous study has shown that the educational level, social and economic status are closely related to the health and disease conditions of population [21]. Based on the distribution of education levels, our study showed that the percentage of esophageal cancer death in high school and below $>60$ years old was higher. The percentage of esophageal cancer death in above high school $\leq 60$ years old was higher. The esophageal cancer death percentage in the various age at two educational levels found that 45 had the highest percentage of esophageal cancer death in "above high school". Age in 65- had the highest percentage of esophageal cancer death in high school and below. These results showed that the percentage of esophageal cancer death was different at various age. In terms of gender, the percentage of male esophageal cancer death was higher than in females at both two educational levels. Irrespective of education level, the percentage of esophageal cancer death in males was higher than females, especially the male with high education level was more significant. In terms of region, the percentage of esophageal cancer death in high school and below was mainly in the eastern regions. The percentage of esophageal cancer death above high school in the mid-west regions was higher than in the east. Overall, the percentage of esophageal cancer death above high school was significantly less than in high school and below in various populations, seemingly reflecting the relation between educational levels and esophageal cancer death. Some researches showed that esophageal cancer is related to smoking, drinking alcohol [22] [23], drinking hot tea [24] and other risk factors. People with high education levels are more likely to maintain good living habits to reduce the impact of the risk factors on esophageal cancer compared with that in low education levels. It can be seen that people with high education level improve their living manner by establish their living habits, which has an indirect effect on occurrence of esophageal cancer. Actually, it has reported that people with higher education pay attention to their physical conditions, maintain good diets, daily living, personal hygiene, and exercise, and 
try to do regular examinations and timely medical treatment, improving their health [8].

\section{Conflicts of Interest}

The authors declare no conflicts of interest regarding the publication of this paper.

\section{References}

[1] Hasegawa-Moriyama, M. and Kanmura, Y. (2020) Perioperative Patient Factors Related to 2-Year Outcome after Esophageal Cancer Surgery: A Retrospective Cohort Study. Open Journal of Anesthesiology, 10, 101-112.

https://doi.org/10.4236/ojanes.2020.104009

[2] He, F., Sha, Y. and Wang, B. (2021) Relationship between Alcohol Consumption and the Risks of Liver Cancer, Esophageal Cancer, and Gastric Cancer in China: Meta-Analysis Based on Case-Control Studies. Medicine, 33, Article No. e26982. https://doi.org/10.1097/MD.0000000000026982

[3] Zhu, J., Ma, S., Chen, R., Xie, S., Liu, Z., Li, X., et al. (2021) Biological Correlates before Esophageal Cancer Screening and after Diagnosis. Scientific Reports, 11, Article No. 17015. https://doi.org/10.1038/s41598-021-96548-5

[4] Li, B., Fu, F., Wang, Z., Zang, Z. and Yu, X. (2020)Analysis of Esophageal Cancer Death Trends in Linzhou City, Henan Province, China, 2005-2016. Chinese Journal Cancer Prevention of and Treatment, 27, 1443-1447.

[5] Wu, Y., He, X., Zhou, Y., Kang, X. and Chang, H. (2021) Investigation and Analysis of Dietary Nutrition and Dietary Habits of Kazakh Esophageal Cancer Patients in Xinjiang. Chinese Journal of the Frontiers of Medical Science (Electronic Version), 13, 73-77.

[6] Sung, H., Ferlay, J., Siegel, R.L., Laversanne, M., Soerjomataram, I., Jemal, A., et al. (2021) Global cancer Statistics 2020: GLOBOCAN Estimates of Incidence and Mortality Worldwide for 36 Cancers in 185 Countries. CA: A Cancer Journal for Clinicians, 71, 209-249. https://doi.org/10.3322/caac.21660

[7] Xue, M. and Zhang, X. (2014) Death Level Analysis on Xinjiang People with Different Cultural Levels Based on the Sixth Census Population. Xinjiang Medical Journal, 44, 20-26.

[8] Hu, P., Sun, F. and Liu, H. (1997) Differences in Death Levels among People with Different Levels of Education. Population \& Economics, 5, 39-45.

[9] Yang, R. (2006) Model of Association of Age, Culture, Marriage, Occupation and Population Mortality. Tibet Science and Technology, 10, 8-10.

[10] Sun, J. and Misumi, J. (2001) A Shimaoka, Stomach Cancer-Related Mortality. European Journal of Cancer Prevention, 10, 61-67. https://doi.org/10.1097/00008469-200102000-00007

[11] Wang, Y. (2012) National Disease Monitoring System Cause of Death Monitoring Data Set 2010. Military Medical Science Publishing House, Beijing.

[12] Hu, Y., Li, Y., Wang, W., Qian, Y., Hui, C., Xin, K., et al. (2014) The Characteristics of Breast Cancer Mortality in Inner Mongolia between 2008 and 2010. Open Journal of Epidemiology, 4, 135-140. https://doi.org/10.4236/ojepi.2014.43019

[13] World Health Organization (2010) ICD-10 Version: 2010. https://icd.who.int/browse10/2010/en\#/C00-C75 
[14] Wu, J. (2021) Surveillance and Analysis of Death Causes of Residents in a Community of Shanghai from 2017 through 2019. Shanghai Journal of Preventive Medicine, 7, 1-11.

[15] International Agency for Research on Cancer (2018) Cancer Today-Powered by GLOBOCAN 2018. https://gco.iarc.fr/today/online-analysis-table?v=2018\&mode

[16] Zheng, L. and Li, H. (2021) Epidemiological Analysis of Esophageal Cancer Deaths among Residents in Fuzhou from 2011 to 2019. Chronic Pathematology Journal, 22, 23-26+29.

[17] Zha, Y., Cheng, S. and Xu, X. (2021) The Incidence and Mortality of Upper Gastrointestinal Tumors in Sichuan Province in 2015. Journal of Preventive Medicine Information, 37, 26-32.

[18] Liu, Y., Li, D. and Liang, D. (2021) An Analysis of the Incidence and Mortality of Esophageal Cancer in Hebei Cancer Registration Area from 2011 to 2016. Practical Oncology Journal, 35, 314-420.

[19] Liu, H., Qiao, L., Qian, Y. and Xi, Y. (2021) The Morbidity and Death Status of Esophageal Cancer in Inner Mongolia in 2016 and Its Trend Analysis from 2012 to 2016. Practical Oncology Journal, 35, 351-356.

[20] Chen, F. and Wang, Y. (2021) Disease Burden and Trends of Esophageal Cancer in China during 1990-2019. China Cancer, 30, 401-407.

[21] Wang, Y., Wang, W., Zheng, S., Yang, L., Zhuo, P. and Yu, Y. (2015) Correlation between Education Level and Common Chronic Diseases in a Residential Community in Xi'an City. Foreign Medical Sciences (Section of Medgeography), 36, 13-16 + 28.

[22] ASGE (American Society for Gastrointestinal Endoscopy) (n.d.) GERD Barrett's Esophagus and the Risk for Esophageal Cancer.

https://www.asge.org/home/for-patients/patient-information/understanding-gerd-b $\underline{\text { arrett-39-s }}$

[23] Polyzos, S.A., Zeglinas, C., Artemaki, F., Doulberis, M., Kazakos, E., Katsinelos, P., et al. (2018) Helicobacter pylori Infection and Esophageal Adenocarcinoma: A Review and a Personal View. Annals of Gastroenterology, 31, 1-6. https://doi.org/10.20524/aog.2017.0213

[24] Lin, S., Xu, G., Chen, Z., Liu, X., Li, J., Ma, L., et al. (2020) Tea Drinking and the Risk of Esophageal Cancer: Focus on Tea Type and Drinking Temperature. European Journal of Cancer Prevention, 29, 382-387. https://doi.org/10.1097/CEJ.0000000000000568 